\title{
Translating Research into Clinical Scale Manufacturing of Mesenchymal Stromal Cells
}

\author{
Karen Bieback, Sven Kinzebach, and Marianna Karagianni \\ Institute of Transfusion Medicine and Immunology, Medical Faculty Mannheim, Heidelberg University, \\ DRK-Blutspendedienst Baden-Wüerttemberg-Hessen, Ludolf-Krehl-Strasse 13-17, D-68167 Mannheim, Germany \\ Correspondence should be addressed to Karen Bieback, karen.bieback@medma.uni-heidelberg.de
}

Received 16 April 2010; Revised 26 November 2010; Accepted 17 December 2010

Academic Editor: Jin Sup Jung

Copyright (C) 2010 Karen Bieback et al. This is an open access article distributed under the Creative Commons Attribution License, which permits unrestricted use, distribution, and reproduction in any medium, provided the original work is properly cited.

It sounds simple to obtain sufficient numbers of cells derived from fetal or adult human tissues, isolate and/or expand the stem cells, and then transplant an appropriate number of these cells into the patient at the correct location. However, translating basic research into routine therapies is a complex multistep process which necessitates product regulation. The challenge relates to managing the expected therapeutic benefits with the potential risks and to balance the fast move to clinical trials with timeconsuming cautious risk assessment. This paper will focus on the definition of mesenchymal stromal cells (MSCs), and challenges and achievements in the manufacturing process enabling their use in clinical studies. It will allude to different cellular sources, special capacities of MSCs, but also to current regulations, with a special focus on accessory material of human or animal origin, like media supplements. As cellular integrity and purity, formulation and lot release testing of the final product, validation of all procedures, and quality assurance are of utmost necessity, these topics will be addressed.

\section{Mesenchymal Stromal Cells in Cellular Therapies}

The vision for cellular therapies in regenerative medicine seems obvious: to replace diseased, dying, or missing cells or tissues with healthy cells [1]. The role of stem cells in this respect is under intense scrutiny, to define principles of organ regeneration and to develop innovative novel methods to treat organ failure. Mesenchymal stem or stromal cells (MSCs) emerge as key candidates for cellular therapies, covering regenerative and immune therapies.

MSCs have a great appeal for cell and immune therapy and tissue engineering for numerous reasons:

(1) they are relatively easy to procure from a variety of tissues [2];

(2) they expand rapidly in cell culture [3];

(3) they show only minor spontaneous differentiation during ex vivo expansion [4];

(4) they are multipotent $[4,5]$;
(5) they form supportive stroma for hematopoiesis and support hematopoietic stem cell engraftment [6];

(6) they seem to be largely immunologically inert, paving the way for allogeneic transplantations [7];

(7) they are immunosuppressive [8];

(8) they secrete numerous trophic factors which modulate inflammation, remodelling, and apoptosis [9].

Based on the initial work of Friedenstein and Caplan, bone marrow-derived MSCs (BM-MSCs) are the ones best described and most advanced in clinical settings. In most comparative studies, BM-MSCs serve as gold standard [2]. For therapeutic applications, easily accessible and highly abundant sources are advantageous. Adipose tissue (AT), most often obtained as lipoaspirate, has emerged as an alternative tissue because cells occur at high frequency and the procurement is less invasive than that of BM aspiration [2]. Blood is obviously the most accessible adult tissue source for cells. Peripheral blood, however, does not contain MSCs in a nonpathological setting, at least not in numbers relevant for clinical scale manufacturing [10]. The same findings still 
hold true for umbilical cord blood (CB) $[2,11]$. An inverse correlation between the gestational age and yields of MSCs is described [12]. Thus MSCs in full term CB are present at only low frequencies which hamper the isolation success $[2,11$, 13]. In contrast to $C B$, isolation success is guaranteed when using the umbilical cord matrix or Wharton's jelly [14]. Fetal tissues are interesting as they seem to contain comparatively immature MSCs expressing pluripotency markers like SSEA3 , and 4, Oct-4, Sox-2 and Nanog [15].

\section{Towards Clinical-Scale Manufacturing of MSCs}

MSCs are increasingly used in many preclinical as well as in some clinical settings for immunomodulation or tissue repair as summarised in more detail in the adjoining sections of this special issue. It is important to note that up to date administration of MSCs proved to be safe and also efficacious in a variety of disorders [16]. Several of these disorders are characterized by both inflammation and tissue defects. Often it cannot be dissected whether efficacy of MSCs is due to their production of trophic factors which stimulate endogenous repair mechanisms, their direct differentiation into various cell types or their immunomodulatory effects. In some of the models, factors released by the MSCs are obviously sufficient to mount a substantial part of the effect [9]. Thus whether efficacy of MSCs requires long-term persistence of MSCs remains to be elucidated.

Translating the rapid progress in stem cell science into innovative cellular therapies led to early and late stage clinical trials. However the complexity of the translational process ranging from the conception, to advanced clinical testing and finally new cell therapeutic drugs revealed a lag behind of standards and guidelines and often suffer from a regulatory burden. Increased scrutiny by the regulatory authorities is mutually dependent from the increasing numbers of cell therapy clinical trials. A variety of organisations responded to that threat to propose minimal set of standards or consensus guidelines [17-21].

Controversies about characteristics and potencies exist most probably due to the fact that different laboratories employ not only different tissue sources, but also extraction methods, culture protocols, and characterisation tools. Any variation may result in isolation and expansion of different subpopulations of cells or may change characteristics of the cells [22]. Thus Dominici et al. proposed minimal criteria defining MSCs [17], namely,

(1) adherence to plastic under standard culture conditions,

(2) expression of CD105, CD73, and CD90, and lack of expression of CD45, CD34, CD14, or CD11b, CD79alpha or CD19 and HLA-DR surface molecules,

(3) differentiation to osteoblasts, adipocytes, and chondroblasts in vitro.

Given the fact that even MSCs used in clinical trials are produced and characterised by a variety of different protocols, reproduction or interpretation of the clinical results may be hampered [21]. Accordingly, standardized protocols have to be developed assuring that the manufactured cells behave solely in the clinically intended purpose and do not exert adverse effects by, for example, uncontrolled differentiation or transformation. Typically MSC can be cultured for 40-50 population doublings until the growth rate declines significantly and cells undergo replicative senescence [23]. Under certain conditions, however, MSCs have been observed to transform spontaneously. Discrepancies were resolved, when laboratories reported that transformation of MSCs was caused by cross-contamination with tumor cell lines $[24,25]$.

Therefore, an essential requirement is that all steps in MSC manufacturing from starting material up to potency testing for the intended indication have to be highly standardized to assure a required and reproducible cellular quality and potency. The challenge for scientists aiming at producing MSCs for clinical trials is to define optimal cell culture conditions to efficiently isolate and ex vivo expand homogenous MSCs while maintaining cellular qualities required for the intended clinical application and minimising risks of adverse events. For example, we recently verified whether AT-MSCs isolated and expanded in human serum (HS) share characteristics with cells cultivated in fetal bovine serum (FBS) $[22,26]$. Although all criteria defined in [17] have been fulfilled, minimal differences were obvious regarding cell size and gene expression profiles. By comparing two human supplements to FBS, we observed that FBS alters gene expression slightly, but in genes categorized to differentiation and adhesion/extracellular matrix [22]. Current studies focus on dissecting in detail whether the supplements alter cellular behaviour in a way affecting the intended therapeutic application.

The therapeutic aim is to repair cell or tissue damage but without the risk of inducing tumors, severe immune reactions, or unwanted tissue development. Thus both safety and efficacy measures shall be considered in the establishment of the manufacturing process. Scarcity of MSCs often requires ex vivo expansion; extensive expansion in consequence may lead to ineffective or degenerated cells [23]. Thus it is important to understand and carefully control the production process and accordingly to define measures that reliably predict safety and efficacy of cell therapeutics.

\section{Regulatory Frameworks}

The employment of adult stem cell types in clinical studies, in general, necessitates formal approval by the respective regulatory body. This approval requires manufacturing, processing, and testing of cellular products according to the current national regulations, including current good tissue practice (GTP), good manufacturing practice (GMP) and good clinical practice (GCP). All cell-based products shall comply with these rules to ensure the product is safe, pure, and potent. GTP and GMP refer to common standards, regulating facilities, personnel, equipment, reagents and supplies, procedures and finally controls (process, final product and laboratory controls). These standards should 
be considered as soon as the development of a cellular product begins. For that reason, regulatory authorities offer investigators their advice to fine-tune the process from the early beginning on.

In Europe, MSCs are classified as advanced therapy medicinal products (ATMPs) [27, 28]. ATMPs include gene therapy medicinal products, somatic cell therapy products (as defined in Directive 2001/83/EC), and tissueengineered products. Cells fall under this regulation in case they have been subjected to substantial manipulation, resulting in a change of their biological characteristics, physiological functions or structural properties relevant for the intended therapeutic application, for example, regeneration, repair, or replacement. ATMP refers to cells or tissues that are not intended to be used for the same essential functions in the recipient as in the donor. This means that MSCs can be considered as somatic cell therapy products or tissue-engineered products depending on the indication and the manipulation during the manufacturing process. Concerning clinical trials with MSCs the rules set out in Article 6(7) and Article 9(4) and (6) of Directive 2001/20/EC shall apply. In the EU the responsible body for clinical trials approval are the health authorities at national level. This is in contrast to USA, where the NIH takes over this part $[28,29]$. In the EU, GMP and GCP are more interrelated than in USA. The European Regulation No. 1394/2007 is effective since December 2008 and is binding in its entirety and directly applicable in all Member States. (Regulation (EC) No 1394/2007 of the European Parliament and of the council http://ec.europa.eu/health/ human-use/advanced-therapies/index_en.htm. The main elements are (i) a centralised marketing authorisation procedure, (ii) the committee for advanced therapies (CAT) as multidisciplinary scientific committed to review the quality, safety and regulatory aspects of ATMP, (iii) technical requirements adapted to particular ATMP characteristics incentives for small- and medium-sized enterprises.) It is in compliance with the 2004/23/EC directive on donation, procurement and testing of human cells and tissues and with the directive 2002/98/EC on human blood and blood components. It is amending the Guideline on cell-based medicinal products (EMEA/CHMP/410869/2006) which focuses on the manufacturing and quality control of cellbased medicinal products as well as their nonclinical and clinical development.

In the US, the FDA (Food and Drug Administration) announced in 1997 the "Proposed Approach to Regulation of Cellular and Tissue-Based Products" (21 CFR 1271). (http://www.accessdata.fda.gov/scripts/cdrh/cfdocs/cfcfr/ CFRSearch.cfm?CFRPart=1271. Sec. 1271.1: "The purpose of this part,..., is to create a unified registration and listing system for establishments that manufacture human cells, tissues, and cellular and tissue-based products (HCT/P's) and to establish donor-eligibility, current good tissue practice, and other procedures to prevent the introduction, transmission, and spread of communicable diseases by HCT/P's".) This became effective in 2005 as rules for Human Cells, Tissues, and Cellular and Tissue-Based Products (HCT/Ps). Although only one cell-based product
(Carticel, autologous cell-based product for cartilage repair manufactured by Genzyme) has been licensed by the FDA, this does not reflect the actual number of trials with cell-based products. Those cell-based therapeutics do not require FDA-approval "that are minimally manipulated, labeled or advertised for homologous use only, and not combined with a drug or device" as specified by Parson, [30]. In contrast, manipulated autologous cells for structural use meet the definition of somatic cell therapy products and require an "investigational new drug" (IND) exemption or the FDA-license approval. In 2007 the "Guidance for Industry: Regulation of Human Cells, Tissues, and Cellular and Tissue-Based Products (HCT/Ps) - Small Entity Compliance Guide" and in 2009 the "Guidance for Industry on Current Good Tissue Practice (cGTP) and Additional Requirements for Manufacturers of Human Cells, Tissues and Cellular and Tissue-based Products" (http://www.fda.gov) have been released. The FDA provides recommendations to support manufacturing establishments of HCT/Ps to better understand and comply with the regulatory framework. Clinical studies employing MSCs underlie the IND mechanism. Accordingly investigator have to make an IND application, which necessitates detailed study protocols, describing the clinical plan as well as the preparation and testing of the therapeutic cell product [31].

Both regulatory frameworks in the EU and USA are to assure safety and thus they require a thorough analysis of all critical steps and aspects in advance. Although there are still differences $[19,28,29]$, the authorities are in contact to further harmonise them. Thus it can be expected that by serving the requirements of one community, the chance is high to fulfil the others as well.

In the following parameters relevant for the manufacture of MSCs are exemplified.

\section{Manufacturing Process}

The manufacturing process is highly fragmented as exemplified in Figure 1, illustrating a GMP-compliant MSC manufacturing process with processing and testing steps. Thus it should be well established and validated before initiating pivotal clinical trials because changes in the manufacturing process may confound clinical trial results.

4.1. Tissue Procurement. In general, the starting material is a critical issue and includes common donor eligibility criteria, like age and viral testing. MSCs have been applied in autologous and allogeneic settings and derived from various tissue sources. Due to an immuno privileged status, a single allogeneic MSC donor may serve for multiple recipients raising the demand for well-defined eligibility criteria [32].

The most often used cellular source to obtain MSCs is $\mathrm{BM}$, followed by AT and then other tissue sources, where we will herein focus on perinatal tissues. BM-derived MSCs are harvested via $\mathrm{BM}$ aspiration after puncture of the donors iliac crest. Aspiration strategy and volume impact the yield of MSCs, so that multiple aspirations from the same site and low aspiration volume $(<8 \mathrm{~mL})$ should be avoided [33]. 

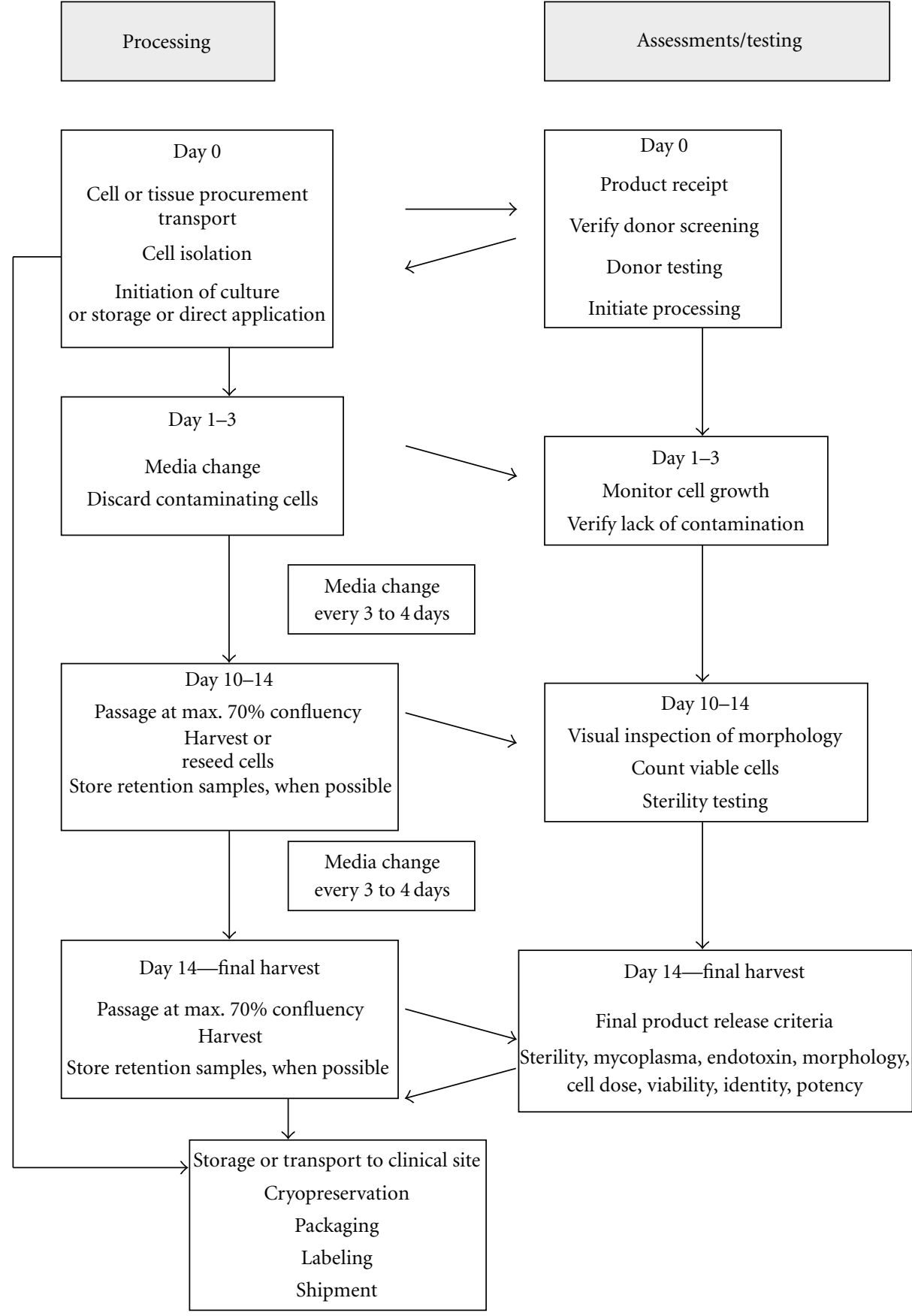

Assessments/testing 
Further hints indicate that donor age impacts the cell yield and the differentiation potential of MSCs [34, 35]. Aspirated $\mathrm{BM}$ volume can be a critical issue as high volumes can result in dilution with blood, too low volumes however demonstrated low to highly heterogeneous yields of MSCs [33]. Some data indicate that MSCs can be isolated from the marrow filter washouts dedicated for hematopoietic stem cell procurement [36]. For isolation, most protocols employ density gradient centrifugation, although the necessity for this step is debated and still under optimisation [37]. Mononuclear cells are then cultivated in MSC culture media until fibroblastoid cells show outgrowth.

AT represents an accessible source of MSCs, often referred to as adipose stem cells (ASCs) [38]. AT can be procured by different techniques, including excision or aspiration, from regions of the body where it is largely present (abdomen, trochanter region, groin, knee). MSCs can be isolated from the tissue by collagenase digestion and centrifugation and cultivation of the stromal vascular fraction to give rise to MSCs [2]. Various studies analysed the impact of harvesting conditions to the cell yield. The yield of ASC does not seem to be affected by the aspiration technique comparing syringe-based or pump-assisted liposuction [39], still there seem to be significant differences between the harvesting sites concerning the adipogenic properties [40] and their susceptibility to apoptosis [41]. Regarding the yield of the harvested ASC, there are controversial results: some report a richer yield of nucleated cells and colony forming units in hip versus abdominal liposuction [39], some others a superior yield of colony forming units after abdominal liposuction compared to hip liposuction [42].

In studies comparing liposuction versus tissue excision, liposuction method turns out to be superior as the cell yield in aspiration material remains stable even after $24 \mathrm{~h}$ storage in contrary to the decreasing cell yield of excisates. In contrast to these results a latter study reveals a higher cell yield and viability after excision [43].

Concerning the influence of the negative pressure during liposuction negative pressure of $-350 \mathrm{mmHg}$ leads to a greater cell yield than lower pressure of $-700 \mathrm{mmHg}$ [44].

Postnatal gestational tissues inherit numerous advantages over MSCs derived from aged adult tissues. Early focus on perinatal tissues harbouring stem cells arose from HSC and MSCs identified in CB $[11,45]$. Subsequently fetal liver, lung, brain, but also villous placenta, fetal membranes as well as amniotic fluid were identified to host MSCs $[13,15]$. Not discussing abortal tissues, in the majority of cases perinatal tissues are discarded at birth, thus cells harvestable without any risk for the baby or its mother. Consequently, there is an unlimited supply, easy access, and minimal ethical/legal issues associated with perinatal tissues. Tissues can be stored for autologous use or allogeneic settings as fetal cells have been demonstrated to be immunoprivileged. Hence CB storage is one strategy widely followed in numerous countries, not only for allogeneic, but also for potential autologous applications [46].

4.2. Manufacture at the Bedside: Volume Reduction and Direct Application. Some therapeutic applications, for example, in cardiac cell therapy, use solely minimally processed tissues, like volume reduced mononuclear cells which can be performed at the patients bedside [47]. This suggests an attractive and probably cost and time reducing option for autologous therapeutic settings and fall under different regulations (the ATMP so-called "hospital exemption") ("Any advanced therapy medicinal product, as defined in Regulation (EC) No 1394/2007, which is prepared on a nonroutine basis according to specific quality standards, and used within the same Member State in a hospital under the exclusive professional responsibility of a medical practitioner, in order to comply with an individual medical prescription for a custom-made product for an individual patient." (EU regulation 1394/2007)). Due to the high precursor frequency especially AT can be processed at the patients' bedside [48]. Still there are different aspects that have to be considered in order to minimize the risks of cellular therapy $[49,50]$. But minimally processed tissues contain a large heterogeneous mixture of stem, progenitor cells, and mature cells, thus of suboptimal composition [51]. A few studies comparing volume reduced to expanded ATderived cell preparations revealed different results $[52,53]$. Consequently, to the current date all clinical applications specifying the use of MSCs have been using culture expanded cells.

\subsection{Manufacture in a GMP-Facility}

4.3.1. Isolation and Expansion. In order to fulfil the regulatory standards the manufacture of a cell product requires the use of safe and pure components and materials. If possible, licensed or GMP-grade reagents should be used, in case of research-grade reagents additional in-house testing may be required to ensure safety and quality. Reagents, including supplements, cytokines, growth factors, used for expansion or differentiation of MSCs should be controlled and documented. Several parameters for ex vivo expansion of MSCs are critical to ensure both good expansion rates as well as maintenance of multipotency of MSCs. These include, for example, starting material, methods used for enrichment or separation, plating density, devices used for MSC culture, media, supplements and growth factors as well as passage number or population doublings [54].

4.3.2. Cell Seeding. Plating densities have emerged as a critical issue for MSC isolation and expansion. Low seeding densities in primary culture seem to be associated with the emergence of more immature progenitor subsets [3]. Moreover, seeding at low densities allows higher expansion rates. For scale-up, accordingly, two different protocols are proposed. In one protocol cells are seeded at nearly clonal levels. This allows expanding the cells to high cumulative population doublings within one passage, but requires large culture area [55]. The other protocol seeds cells at higher concentrations. Due to reduced possible population doublings, this procedure necessitates a second passage, which, however, facilitates efficient depletion of contaminating cells [56]. 
4.3.3. Media and Supplements. Culture conditions shall retain or even accelerate regenerative and trophic properties of MSCs. The variety in protocols is immense and a standard has not yet been defined. The classical media composition consists of a basal medium (DMEM or alphaMEM) and 10\%-20\% supplement, most often FBS, which is available in GMP grade allowed for clinical use. The ongoing debate regarding xenogenic, especially ruminant proteins in pharmaceuticals also applies to MSCs. FBS bears the risk of transferring xenogenic, potentially infectious, or immunogenic proteins. Immunogenicity against FBS proteins has demonstrated to compromise the therapeutic benefit $[57,58]$. Thus although GMP-compliant FBS batches are available and used in clinical grade manufacturing the regulatory authorities ask to replace FBS with a nonxenogeneic alternative if possible for the manufacturer.

Up to now no completely serum-free media formulation in clinical-grade is available which allows both isolation (critical issue: attachment factors) and expansion of MSC [59]. Serum proteins provide not only nutrients but also essential attachment factors. Several laboratories have proposed the use of human components to supplement MSC growth medium. Here either autologous or allogeneic HS or platelet-derived factors have been evaluated [26, 54, 59, 60]. HS as well as platelet lysate are very crude protein cocktails. Essential growth factors for optimal MSC culture have not yet been defined. PDGF, EGF, TGF- $\beta$, and IGF have been subjected to investigation. Basic FGF has demonstrated most promising effects in expanding MSCs whilst maintaining stem cell properties and reducing replicative senescence [61]. Recently, Pytlík et al. described a HS and growth factor supplemented clinical-grade medium which allowed for high cell expansion mediated by loss of contact inhibition [62].

Any significant change in the production process may affect cellular functions. Accordingly, it is necessary to analyse the qualities of MSCs in comparability studies to ensure that cellular qualities are not compromised. Within a variety of publications, pooled human platelet lysate emerged as suitable alternative for BM-MSC isolation and expansion [26]. Our own data indicate that for ASC in contrast pooled HS has better effects on expansion [60]. But as specified above, it has to be determined whether therapeutic qualities are modified, improved or impaired. It is conceivable that depending on the clinical setting different protocols (cellular sources, manufacturing protocols, quality control/potency assays) come into place to derive the optimal product.

4.3.4. Devices for Expansion. MSCs grow as adherent cells until reaching confluency and then further expand by serial passaging. Therefore the number of cells which can be harvested in an ex vivo expansion culture is determined by the surface area. Typically MSCs are cultivated in conventional monolayer cultures. In order to achieve a large surface area multilayered cell factories are used $[55,56]$. This approach is labour intensive and money consuming. Also by using bioreactors it became possible to expand MSCs [63, 64]. As closed systems should be preferred in a GMP-setting,
Rojewski et al. report a fully automated bioreactor allowing large-scale GMP-compliant manufacturing [65].

A critical issue is the proliferative age of MSCs: MSCs have a restricted lifespan and reach a senescent state in which cellular functions become diminished and the risk for accumulating mutations rises $[32,66]$. Most often proliferative capacity is expressed by passage numbers. Passage numbers in contrast to population doublings do not describe the de facto proliferation history which is critical when reaching a certain—not yet well—defined time point (maximum 30 population doublings) [66].

4.3.5. Storage or Cryopreservation. After isolation, volumereduced cells or ex vivo-culture expanded cells can be transplanted directly or stored for long term under low temperature conditions. A variety of studies investigated the effects of storage conditions and cryopreservation methods and media [67-69] demonstrating that MSCs can be cryopreserved and thawed without loss of function [70]. Cryopreservation gives the only opportunity to perform time-consuming release tests prior to clinical application of the cells, hardly possible to achieve when the cell product is intended for immediate release.

4.4. Product Specification. As always it is necessary to weigh carefully the risk against the potential benefits of stem cell therapy. Potential risks can be reduced when applying appropriate release tests capable of ensuring safety, efficacy and consistency of the product. Cell-based products require special considerations on the manufacturing process, especially when they have to be applied immediately. In this situation it is impossible to obtain results of laboratory tests prior to the cell application, thus a limited set of controls has to ensure that the product fulfils all the predefined quality criteria. For cellular products in general sufficient numbers of viable, high quality cells are required. These can be easily documented by simple, rapid cell viability tests.

Cell-based products cannot be sterilized to avoid transferring infectious diseases. By using human and/or xenogenic material, there is a potential for adventitious agent contamination, thus testing for bacteria, fungi, mycoplasma and viruses should be performed. Regardless of the use in autologous or allogeneic settings an increased attention to assure aseptic processing is mandatory.

As indicated above, safety might be affected as prolonged ex vivo culture can accumulate aberrations. But only anecdotal studies indicate that MSCs may undergo spontaneous transformation, associated with chromosomal aberrations, induction of oncogenes and tumorigenicity after transplantation $[23,71]$. Clinical experience indicates that cells, when harvested before onset of senescence, demonstrate extremely low probability of tumor formation [66]. Current testing systems including karyotype analyses, FISH, comparative genomic hybridization, or PCR to check for tumor marker expression may not be sensitive enough to detect the expected low proportion of affected cells [72], but even occurrence of alterations, like aneuploidity does not predict transformation, as recently demonstrated by 
Tarte et al. These data nevertheless helped to refine control assays, easily to perform, to control cell cycle/senescence and transformation pathways by, for example, PCR for p14, p16 ${ }^{\text {Ink4a }}$, p21, p53, hTERT, and oncogenes like c-myc.

Further clinical safety concerns relate to possible ectopic tissue formation or other adverse events in the recipient. Despite the fact that in general no adverse reactions have been recorded, this possibility cannot be neglected yet. Mice treated locally with MSCs for myocardial infarction developed calcifications [73]. Further the relatively big cell size has been observed at times to cause pulmonary sequestration and embolism after intravascular transplantation [74]. Furthermore the protocol for cell application can affect transplantation as recently demonstrated when comparing different cell suspension media [75]. Finally, although therapeutically intended in some clinical settings, for example, to prevent or treat GvHD, the immunomodulatory capacities may also favour tumor growth or formation of metastasis, as observed in animal models [76-79].

For the EU and USA, the criteria for test procedures differ. Test procedures, for example, for sterility test, have to be approved by the FDA or the national regulatory authorities in Europe. But as the requirements are not identical, the international conference of harmonisation (ICH) intends to harmonise them (for more information, see respective homepages).

4.5. Identity and Impurities. The identity of cell-based products can be ensured where necessary by genotypic or phenotypic analysis. In MSC cultures, the fraction of cells displaying identity markers (mesenchymal markers) and the identification of contaminating cells (hematopoietic markers) can be easily and rapidly quantified by flow cytometric analyses [17, 80]. Above this morphological assessment of fibroblastic phenotype and proliferation can be easily documented in expansion cultures.

Product-related impurities have to be determined and specified, including endotoxin testing [81]. Where appropriate, impurities relating to, for example, degradation products from structural or matrix components shall be specified, as well as process-related impurities derived from added bioactive components.

4.6. Potency. Product characterisation has to consider the functional capacities related to the intended clinical use. The minimal criteria of the ISCT require to control the capacity of MSCs to adhere to normal plastic culture surfaces, to generate cells with a fibroblastic phenotype, which express or fail to express a typical set of surface markers, and to exhibit multilineage differentiation potential, at least into the osteo-, adipo-, and chondrogenic lineage [17]. Although every laboratory employs these assays, the assays are time consuming and far from being standardized yet, so comparison between laboratories and also the read-out of clinical data is hampered [80]. As mentioned before development of preclinical efficacy tests in the investigated indication are highly desirable as MSCs appear to employ different modes of function according to the intended use.
Depending on the clinical intention, the following assays can be performed to assess potency, but it has to be kept in mind that none of these assays has been directly correlated to therapeutic efficiency [32].

Clonogenicity. The CFU-F assay is a suitable but not standardized tool to quantify precursor frequencies. Analysis demands for appropriate dilution to clonal levels as CFU-F frequencies do not follow a linear regression correlated to the input cell number $[54,55]$.

Differentiation Potential. The multilineage differentiation potential is a hallmark of MSCs, but discussed in detail elsewhere [4, 5, 82]. In vitro assays can be performed using self-made or commercially available induction media. However, it is increasingly discussed whether and to which extent in vitro data correlate to in vivo differentiation potential $[82,83]$.

Immunomodulatory Capacities. The perspective of modulating immune responses against allo- and possible also autoantigens has rendered MSCs an attractive population of cells for immune therapies. In vitro, assays have been established to quantify the expression of surface molecules, such as HLA class I and II and costimulatory molecules. In cocultures with peripheral blood mononuclear cells, MSCs do not elicit an alloreactive response. Furthermore, when added as third party in mixed lymphocyte reactions or mitogen-driven cultures, MSCs dose dependently inhibit immune cell responses. Very low concentrations of MSCs however can stimulate immune responses [84]. While this has not yet been observed in vivo, too low numbers of MSCs transplanted may accelerate the immune response rather than mitigate it in GvHD or autoimmune settings.

Hematopoiesis/Stromal Support. The beneficial effects of cotransplanting MSCs in haematological settings have already been demonstrated [85]. This effect can be assayed in vitro in coculture experiments using hematopoietic stem cells and MSCs and thus may be an adequate quality control system for this therapeutic indication [86].

Trophic Support. In a variety of settings MSCs showed promising therapeutic effects even though the transfused cells were-if at all-only barely detectable in the injured organs. Recent data further demonstrated that especially secreted factors actively modulate debilitating local inflammatory reactions. Reduction of apoptosis, and fibrotic tissue remodelling as well as recruitment of local resident regenerative cells contributed to the beneficial effects $[9,87]$. Accordingly some studies already demonstrate therapeutic effects when infusing MSC conditioned medium instead of cells $[88,89]$. Depending on the therapeutical setting, analysing the secretome by quantifying levels of chemo- or cytokines may subsequently emerge as additional potency assay $[26,60]$. 
4.7. Validation. Safety and efficacy of a cellular product has to be demonstrated prior to their administration in humans. MSC application in clinical settings has progressed fast with 128 hits entering "mesenchymal stem cells" as search term under http://www.clinicaltrials.org. Nevertheless, there is a trend to go back from bedside to bench to better characterise and improve MSCs and importantly to standardise protocols for isolation, expansion, and finally characterisation. Changes in vitro necessitate translating them into clinical protocols. Thus it is a critical point to coordinate the clinicians needs with the researchers option in close interaction with the manufacturing laboratories, who overview the margin framed by the regulatory authorities. Any significant changes in the manufacturing protocols require validation in vitro and in appropriate in vivo animal models to assure safety and efficacy [28] as well as absence of toxicity (related to dedifferentiation or unwanted differentiation, migration to unwanted sites). All animal models have inherent limitations, like, for example, the application of human cells in a xenogenic milieu [82]. This requires the use of severely immunocompromised small animals preventing contrariwise analysis of immunological reactions. Furthermore for a variety of disease models, for example, in orthopaedics, small animals are not capable of modelling the disease. Consequently, one has to define a compromise between all requirements: clinical, regulatory, and laboratory to agree on appropriate validation strategies.

\section{Conclusion}

In the recent years numerous advancements led to the employment of MSCs in a variety of therapeutic indications raising expectations and hope. Although numerous clinical trials have been initiated worldwide (http://clinicaltrials.gov), standardized protocols for isolation, expansion, and characterisation, especially those on GMP-grade, seem to lag behind. The sum of clinical studies has supported safety and efficacy by demonstrating absence of major side effects associated with success reports. The lack of conformity between manufacturing protocols however is considered as potential threat to further development of the field. The heterogeneity of isolation, expansion, and characterisation protocols remains as obstacle. Thus to ensure the success of MSC-based therapies, we regard as a major critical issue to standardise and harmonise translational protocols in order to develop manufacturing processes along-side with developing therapies and not thereafter.

\section{Acknowledgments}

This work was supported by research funds of the German Federal Ministry of Education and Research (01GN0531 and 01GN0939) and additionally by a project commissioned by the European Community ("CASCADE" HEALTH-F52009-223236).

\section{References}

[1] G. Q. Daley and D. T. Scadden, "Prospects for stem cell-based therapy," Cell, vol. 132, no. 4, pp. 544-548, 2008.

[2] S. Kern, H. Eichler, J. Stoeve, H. Klüter, and K. Bieback, "Comparative analysis of mesenchymal stem cells from bone marrow, umbilical cord blood, or adipose tissue," Stem Cells, vol. 24, no. 5, pp. 1294-1301, 2006.

[3] I. Sekiya, B. L. Larson, J. R. Smith, R. Pochampally, J. G. Cui, and D. J. Prockop, "Expansion of human adult stem cells from bone marrow stroma: conditions that maximize the yields of early progenitors and evaluate their quality," Stem Cells, vol. 20, no. 6, pp. 530-541, 2002.

[4] M. F. Pittenger, A. M. Mackay, S. C. Beck et al., "Multilineage potential of adult human mesenchymal stem cells," Science, vol. 284, no. 5411, pp. 143-147, 1999.

[5] D. G. Phinney and D. J. Prockop, "Concise review: mesenchymal stem/multipotent stromal cells: the state of transdifferentiation and modes of tissue repair-current views," Stem Cells, vol. 25, no. 11, pp. 2896-2902, 2007.

[6] F. Dazzi, R. Ramasamy, S. Glennie, S. P. Jones, and I. Roberts, "The role of mesenchymal stem cells in haemopoiesis," Blood Reviews, vol. 20, no. 3, pp. 161-171, 2006.

[7] K. Le Blanc, C. Tammik, K. Rosendahl, E. Zetterberg, and O. Ringdén, "HLA expression and immunologic properties of differentiated and undifferentiated mesenchymal stem cells," Experimental Hematology, vol. 31, no. 10, pp. 890-896, 2003.

[8] K. Le Blanc and O. Ringdén, "Immunobiology of human mesenchymal stem cells and future use in hematopoietic stem cell transplantation," Biology of Blood and Marrow Transplantation, vol. 11, no. 5, pp. 321-334, 2005.

[9] A. I. Caplan and J. E. Dennis, "Mesenchymal stem cells as trophic mediators," Journal of Cellular Biochemistry, vol. 98, no. 5, pp. 1076-1084, 2006.

[10] Q. He, C. Wan, and G. Li, "Concise review: multipotent mesenchymal stromal cells in blood," Stem Cells, vol. 25, no. 1, pp. 69-77, 2007.

[11] K. Bieback, S. Kern, H. Klüter, and H. Eichler, "Critical parameters for the isolation of mesenchymal stem cells from umbilical cord blood," Stem Cells, vol. 22, no. 4, pp. 625-634, 2004.

[12] M. J. Javed, L. E. Mead, D. Prater et al., "Endothelial colony forming cells and mesenchymal stem cells are enriched at different gestational ages in human umbilical cord blood," Pediatric Research, vol. 64, no. 1, pp. 68-73, 2008.

[13] K. Bieback and H. Klüter, "Mesenchymal stromal cells from umbilical cord blood," Current Stem Cell Research and Ther$a p y$, vol. 2, no. 4, pp. 310-323, 2007.

[14] H. S. Wang, S. C. Hung, S. T. Peng et al., "Mesenchymal stem cells in the Wharton's jelly of the human umbilical cord," Stem Cells, vol. 22, no. 7, pp. 1330-1337, 2004.

[15] O. Parolini, F. Alviano, G. P. Bagnara et al., "Concise review: isolation and characterization of cells from human term placenta: outcome of the first international Workshop on Placenta Derived Stem Cells," Stem Cells, vol. 26, no. 2, pp. 300-311, 2008.

[16] L. Sensebé, M. Krampera, H. Schrezenmeier, P. Bourin, and R. Giordano, "Mesenchymal stem cells for clinical application," Vox Sanguinis, vol. 98, no. 2, pp. 93-107, 2010.

[17] M. Dominici, K. Le Blanc, I. Mueller et al., "Minimal criteria for defining multipotent mesenchymal stromal cells. The International Society for Cellular Therapy position statement," Cytotherapy, vol. 8, no. 4, pp. 315-317, 2006. 
[18] L. Ährlund-Richter, M. De Luca, D. R. Marshak, M. Munsie, A. Veiga, and M. Rao, "Isolation and production of cells suitable for human therapy: challenges ahead," Cell Stem Cell, vol. 4, no. 1, pp. 20-26, 2009.

[19] K. Martell, A. Trounson, and E. Baum, "Stem cell therapies in clinical trials: workshop on best practices and the need for harmonization," Cell Stem Cell, vol. 7, no. 4, pp. 451-454, 2010.

[20] D. Lau, U. Ogbogu, B. Taylor, T. Stafinski, D. Menon, and T. Caulfield, "Stem cell clinics online: the direct-to-consumer portrayal of stem cell medicine," Cell Stem Cell, vol. 3, no. 6, pp. 591-594, 2008.

[21] L. W. Miller, "Stem cell therapy trials: a call for standardization," Journal of Cardiovascular Translational Research, vol. 1, pp. 185-187, 2008.

[22] K. Bieback, V. A.-T. Ha, A. Hecker et al., "Altered gene expression in human adipose stem cells cultured with fetal bovine serum compared to human supplements," Tissue Engineering Part A, vol. 16, no. 11, pp. 3467-3484, 2010.

[23] G. Lepperdinger, R. Brunauer, A. Jamnig, G. Laschober, and M. Kassem, "Controversial issue: is it safe to employ mesenchymal stem cells in cell-based therapies?" Experimental Gerontology, vol. 43, no. 11, pp. 1018-1023, 2008.

[24] S. Garcia, M. C. Martín, R. de la Fuente, J. C. Cigudosa, J. Garcia-Castro, and A. Bernad, "Pitfalls in spontaneous in vitro transformation of human mesenchymal stem cells," Experimental Cell Research, vol. 316, no. 9, pp. 1648-1650, 2010.

[25] A. Torsvik, G. V. Røsland, A. Svendsen et al., "Spontaneous malignant transformation of human mesenchymal stem cells reflects cross-contamination: putting the research field on track-letter," Cancer Research, vol. 70, no. 15, pp. 6393-6396, 2010.

[26] K. Bieback, A. Hecker, A. Kocaömer et al., "Human alternatives to fetal bovine serum for the expansion of mesenchymal stromal cells from bone marrow," Stem Cells, vol. 27, no. 9, pp. 2331-2341, 2009.

[27] I. C. M. Slaper-Cortenbach, "Current regulations for the production of multipotent mesenchymal stromal cells for clinical application," Transfusion Medicine and Hemotherapy, vol. 35, no. 4, pp. 295-298, 2008.

[28] C. K. Schneider, P. Salmikangas, B. Jilma et al., "Challenges with advanced therapy medicinal products and how to meet them," Nature Reviews Drug Discovery, vol. 9, no. 3, pp. 195201, 2010.

[29] G. Deal, "Stem cell therapy regulations: the US vs the EU," Regulatory Rapporteur, vol. 6, pp. 4-6, 2009.

[30] A. Parson, "The Long Journey from Stem Cells to Medical Product," Cell, vol. 125, no. 1, pp. 9-11, 2006.

[31] A. Gee, "Mesenchymal stem-cell therapy in a regulated environment," Cytotherapy, vol. 3, no. 5, pp. 397-398, 2001.

[32] L. Sensebe, P. Bourin, and K. Tarte, "Good manufacturing practices production of mesenchymal stem/stromal cells," Human Gene Therapy. In press.

[33] E. M. Fennema, A. J. S. Renard, A. Leusink, C. A. van Blitterswijk, and J. de Boer, "The effect of bone marrow aspiration strategy on the yield and quality of human mesenchymal stem cells," Acta Orthopaedica, vol. 80, no. 5, pp. 618-621, 2009.

[34] S. Sethe, A. Scutt, and A. Stolzing, "Aging of mesenchymal stem cells," Ageing Research Reviews, vol. 5, no. 1, pp. 91-116, 2006.
[35] P. Coipeau, P. Rosset, A. Langonn et al., "Impaired differentiation potential of human trabecular bone mesenchymal stromal cells from elderly patients," Cytotherapy, vol. 11, no. 5, pp. 584-594, 2009.

[36] C. Capelli, M. Domenghini, G. Borleri et al., "Human platelet lysate allows expansion and clinical grade production of mesenchymal stromal cells from small samples of bone marrow aspirates or marrow filter washouts," Bone Marrow Transplantation, vol. 40, no. 8, pp. 785-791, 2007.

[37] P. Horn, S. Bork, A. Diehlmann et al., "Isolation of human mesenchymal stromal cells is more efficient by red blood cell lysis," Cytotherapy, vol. 10, no. 7, pp. 676-685, 2008.

[38] P. A. Zuk, M. Zhu, P. Ashjian et al., "Human adipose tissue is a source of multipotent stem cells," Molecular Biology of the Cell, vol. 13, no. 12, pp. 4279-4295, 2002.

[39] J. K. Fraser, I. Wulur, Z. Alfonso, M. Zhu, and E. S. Wheeler, "Differences in stem and progenitor cell yield in different subcutaneous adipose tissue depots," Cytotherapy, vol. 9, no. 5, pp. 459-467, 2007.

[40] T. Tchkonia, N. Giorgadze, T. Pirtskhalava et al., "Fat depot origin affects adipogenesis in primary cultured and cloned human preadipocytes," American Journal of Physiology, vol. 282, no. 5, pp. R1286-R1296, 2002.

[41] C. U. Niesler, K. Siddle, and J. B. Prins, "Human preadipocytes display a depot-specific susceptibility to apoptosis," Diabetes, vol. 47, no. 8, pp. 1365-1368, 1998.

[42] W. J. F. M. Jurgens, M. J. Oedayrajsingh-Varma, M. N. Helder et al., "Effect of tissue-harvesting site on yield of stem cells derived from adipose tissue: implications for cell-based therapies," Cell and Tissue Research, vol. 332, no. 3, pp. 415426, 2008.

[43] N. Torio-Padron, A. M. Huotari, S. U. Eisenhardt, J. Borges, and G. B. Stark, "Comparison of pre-adipocyte yield, growth and differentiation characteristics from excised versus aspirated adipose tissue," Cells Tissues Organs, vol. 191, no. 5, pp. 365-371, 2010.

[44] A. Mojallal, C. Auxenfans, C. Lequeux, F. Braye, and O. Damour, "Influence of negative pressure when harvesting adipose tissue on cell yield of the stromal-vascular fraction," Bio-Medical Materials and Engineering, vol. 18, no. 4-5, pp. 193-197, 2008.

[45] K. Bieback, S. Kern, A. Kocaömer, K. Ferlik, and P. Bugert, "Comparing mesenchymal stromal cells from different human tissues: bone marrow, adipose tissue and umbilical cord blood," Bio-Medical Materials and Engineering, vol. 18, no. 1, pp. S71-S76, 2008.

[46] P. Rubinstein, "Cord blood banking for clinical transplantation," Bone Marrow Transplantation, vol. 44, no. 10, pp. 635642, 2009.

[47] S. Dimmeler, J. Burchfield, and A. M. Zeiher, "Cell-based therapy of myocardial infarction," Arteriosclerosis, Thrombosis, and Vascular Biology, vol. 28, no. 2, pp. 208-216, 2008.

[48] H. J. Duckers, K. Pinkernell, A. M. Milstein, and M. H. Hedrick, "The Bedside Celution system for isolation of adipose derived regenerative cells," EuroInterventio, vol. 2, pp. 395-398, 2006.

[49] P. J. Mishra, P. J. Mishra, J. W. Glod, and D. Banerjee, "Mesenchymal stem cells: flip side of the coin," Cancer Research, vol. 69, no. 4, pp. 1255-1258, 2009.

[50] J. Stagg and J. Galipeau, "Immune plasticity of bone marrowderived mesenchymal stromal cells," Handbook of Experimental Pharmacology, no. 180, pp. 45-66, 2007. 
[51] A. V. Cuomo, M. Virk, F. Petrigliano, E. F. Morgan, and J. R. Lieberman, "Mesenchymal stem cell concentration and bone repair: potential pitfalls from bench to bedside," Journal of Bone and Joint Surgery. American, vol. 91, no. 5, pp. 10731083, 2009.

[52] D. Garcia-Olmo, D. Herreros, M. Pascual et al., "Treatment of enterocutaneous fistula in Crohn's disease with adiposederived stem cells: a comparison of protocols with and without cell expansion," International Journal of Colorectal Disease, vol. 24, no. 1, pp. 27-30, 2009.

[53] N. H. Riordan, T. E. Ichim, W. P. Min et al., "Non-expanded adipose stromal vascular fraction cell therapy for multiple sclerosis," Journal of Translational Medicine, vol. 7, article 29, 2009.

[54] K. Bieback, K. Schallmoser, H. Klüter, and D. Strunk, “Clinical protocols for the isolation and expansion of mesenchymal stromal cells," Transfusion Medicine and Hemotherapy, vol. 35, no. 4, pp. 286-294, 2008.

[55] K. Schallmoser, E. Rohde, A. Reinisch et al., "Rapid largescale expansion of functional mesenchymal stem cells from unmanipulated bone marrow without animal serum," Tissue Engineering Part C, vol. 14, no. 3, pp. 185-196, 2008.

[56] L. Sensebé, "Clinical grade production of mesenchymal stem cells," Bio-Medical Materials and Engineering, vol. 18, no. 1, pp. S3-S10, 2008.

[57] E. M. Horwitz, P. L. Gordon, W. K. K. Koo et al., "Isolated allogeneic bone marrow-derived mesenchymal cells engraft and stimulate growth in children with osteogenesis imperfecta: implications for cell therapy of bone," Proceedings of the National Academy of Sciences of the United States of America, vol. 99, no. 13, pp. 8932-8937, 2002.

[58] M. Sundin, O. Ringdén, B. Sundberg, S. Nava, C. Götherström, and K. Le Blanc, "No alloantibodies against mesenchymal stromal cells, but presence of anti-fetal calf serum antibodies, after transplantation in allogeneic hematopoietic stem cell recipients," Haematologica, vol. 92, no. 9, pp. 1208-1215, 2007.

[59] F. Mannello and G. A. Tonti, "Concise review: no breakthroughs for human mesenchymal and embryonic stem cell culture: conditioned medium, feeder layer, or feederfree; medium with fetal calf serum, human serum, or enriched plasma; serum-free, serum replacement nonconditioned medium, or ad hoc formula? All that glitters is not gold!," Stem Cells, vol. 25, no. 7, pp. 1603-1609, 2007.

[60] A. Kocaoemer, S. Kern, H. Klüter, and K. Bieback, "Human $\mathrm{AB}$ serum and thrombin-activated platelet-rich plasma are suitable alternatives to fetal calf serum for the expansion of mesenchymal stem cells from adipose tissue," Stem Cells, vol. 25, no. 5, pp. 1270-1278, 2007.

[61] S. Tsutsumi, A. Shimazu, K. Miyazaki et al., "Retention of multilineage differentiation potential of mesenchymal cells during proliferation in response to FGF," Biochemical and Biophysical Research Communications, vol. 288, no. 2, pp. 413419, 2001.

[62] R. Pytlík, D. Stehlík, T. Soukup et al., "The cultivation of human multipotent mesenchymal stromal cells in clinical grade medium for bone tissue engineering," Biomaterials, vol. 30, no. 20, pp. 3415-3427, 2009.

[63] X. Chen, H. Xu, C. Wan, M. McCaigue, and G. Li, "Bioreactor expansion of human adult bone marrow-derived mesenchymal stem cells," Stem Cells, vol. 24, no. 9, pp. 2052-2059, 2006.

[64] M. H. Gastens, K. Goltry, W. Prohaska et al., "Good manufacturing practice-compliant expansion of marrow-derived stem and progenitor cells for cell therapy," Cell Transplantation, vol. 16, no. 7, pp. 685-696, 2007.

[65] M. Rojewski, J. Dausend, G. Schmidtke-Schrezenmeier, and H. Schrezenmeier, "A standardized protocol for GMP compliant expansion of MSC from BM in an animal component free system," Vox Sanguinis, vol. 99, p. 43, 2010.

[66] D. J. Prockop, M. Brenner, W. E. Fibbe et al., "Defining the risks of mesenchymal stromal cell therapy," Cytotherapy, vol. 12, no. 5, pp. 576-578, 2010.

[67] P. Todorov, E. Hristova, R. Konakchieva, A. Michova, and J. Dimitrov, "Comparative studies of different cryopreservation methods for mesenchymal stem cells derived from human fetal liver," Cell Biology International, vol. 34, no. 5, pp. 455$462,2010$.

[68] S. L. Gordon, S. R. Oppenheimer, A. M. Mackay, J. Brunnabend, I. Puhlev, and F. Levine, "Recovery of human mesenchymal stem cells following dehydration and rehydration," Cryobiology, vol. 43, no. 2, pp. 182-187, 2002.

[69] R. Pal, M. Hanwate, and S. M. Totey, "Effect of holding time, temperature and different parenteral solutions on viability and functionality of adult bone marrow-derived mesenchymal stem cells before transplantation," Journal of Tissue Engineering and Regenerative Medicine, vol. 2, no. 7, pp. 436-444, 2008.

[70] S. P. Bruder, N. Jaiswal, and S. E. Haynesworth, "Growth kinetics, self-renewal, and the osteogenic potential of purified human mesenchymal stem cells during extensive subcultivation and following cryopreservation," Journal of Cellular Biochemistry, vol. 64, no. 2, pp. 278-294, 1997.

[71] F. Tirode, K. Laud-Duval, A. Prieur, B. Delorme, P. Charbord, and O. Delattre, "Mesenchymal stem cell features of Ewing tumors," Cancer Cell, vol. 11, no. 5, pp. 421-429, 2007.

[72] K. Tarte, J. Gaillard, J. J. Lataillade et al., "Clinical-grade production of human mesenchymal stromal cells: occurrence of aneuploidy without transformation," Blood, vol. 115, no. 8, pp. 1549-1553, 2010.

[73] M. Breitbach, T. Bostani, W. Roell et al., "Potential risks of bone marrow cell transplantation into infarcted hearts," Blood, vol. 110, no. 4, pp. 1362-1369, 2007.

[74] D. Furlani, M. Ugurlucan, L. Ong et al., "Is the intravascular administration of mesenchymal stem cells safe?. Mesenchymal stem cells and intravital microscopy," Microvascular Research, vol. 77, no. 3, pp. 370-376, 2009.

[75] E. Deak, B. Rüster, L. Keller et al., "Suspension medium influences interaction of mesenchymal stromal cells with endothelium and pulmonary toxicity after transplantation in mice," Cytotherapy, vol. 12, no. 2, pp. 260-264, 2010.

[76] A. E. Karnoub, A. B. Dash, A. P. Vo et al., "Mesenchymal stem cells within tumour stroma promote breast cancer metastasis," Nature, vol. 449, no. 7162, pp. 557-563, 2007.

[77] E. L. Spaeth, J. L. Dembinski, A. K. Sasser et al., "Mesenchymal stem cell transition to tumor-associated fibroblasts contributes to fibrovascular network expansion and tumor progression," PLoS One, vol. 4, no. 4, Article ID e4992, 2009.

[78] M. Galiè, G. Konstantinidou, D. Peroni et al., "Mesenchymal stem cells share molecular signature with mesenchymal tumor cells and favor early tumor growth in syngeneic mice," Oncogene, vol. 27, no. 18, pp. 2542-2551, 2008.

[79] F. Djouad, C. Bony, F. Apparailly, P. Louis-Plence, C. Jorgensen, and D. Noël, "Earlier onset of syngeneic tumors in the presence of mesenchymal stem cells," Transplantation, vol. 82, no. 8, pp. 1060-1066, 2006.

[80] M. T. Rojewski, B. M. Weber, and H. Schrezenmeier, "Phenotypic characterization of mesenchymal stem cells from various 
tissues," Transfusion Medicine and Hemotherapy, vol. 35, no. 3, pp. 168-184, 2008.

[81] S. Soncin, V. Lo Cicero, G. Astori et al., "A practical approach for the validation of sterility, endotoxin and potency testing of bone marrow mononucleated cells used in cardiac regeneration in compliance with good manufacturing practice," Journal of Translational Medicine, vol. 7, p. 78, 2009.

[82] P. Bianco, P. G. Robey, and P. J. Simmons, "Mesenchymal stem cells: revisiting history, concepts, and assays," Cell Stem Cell, vol. 2, no. 4, pp. 313-319, 2008.

[83] J. S. Burns, P. L. Rasmussen, K. H. Larsen, H. D. Schrøder, and M. Kassem, "Parameters in three-dimensional osteospheroids of telomerized human mesenchymal (Stromal) stem cells grown on osteoconductive scaffolds that predict in vivo boneforming potential," Tissue Engineering Part A, vol. 16, no. 7, pp. 2331-2342, 2010.

[84] K. Le Blanc, L. Tammik, B. Sundberg, S. E. Haynesworth, and O. Ringdén, "Mesenchymal stem cells inhibit and stimulate mixed lymphocyte cultures and mitogenic responses independently of the major histocompatibility complex," Scandinavian Journal of Immunology, vol. 57, no. 1, pp. 11-20, 2003.

[85] O. N. Koç, S. L. Gerson, B. W. Cooper et al., "Rapid hematopoietic recovery after coinfusion of autologous-blood stem cells and culture-expanded marrow mesenchymal stem cells in advanced breast cancer patients receiving high-dose chemotherapy," Journal of Clinical Oncology, vol. 18, no. 2, pp. 307-316, 2000.

[86] W. Wagner, R. Saffrich, and A. D. Ho, "The stromal activity of mesenchymal stromal cells," Transfusion Medicine and Hemotherapy, vol. 35, no. 3, pp. 185-193, 2008.

[87] E. M. Horwitz and W. R. Prather, "Cytokines as the major mechanism of mesenchymal stem cell clinical activity: expanding the spectrum of cell therapy," Israel Medical Association Journal, vol. 11, no. 4, pp. 209-211, 2009.

[88] K. S. Park, Y. S. Kim, J. H. Kim et al., "Trophic molecules derived from human mesenchymal stem cells enhance survival, function, and angiogenesis of isolated islets after transplantation," Transplantation, vol. 89, no. 5, pp. 509-517, 2010.

[89] Y. O. Joo, K. K. Mee, S. S. Mi et al., "The anti-inflammatory and anti-angiogenic role of mesenchymal stem cells in corneal wound healing following chemical injury," Stem Cells, vol. 26, no. 4, pp. 1047-1055, 2008. 

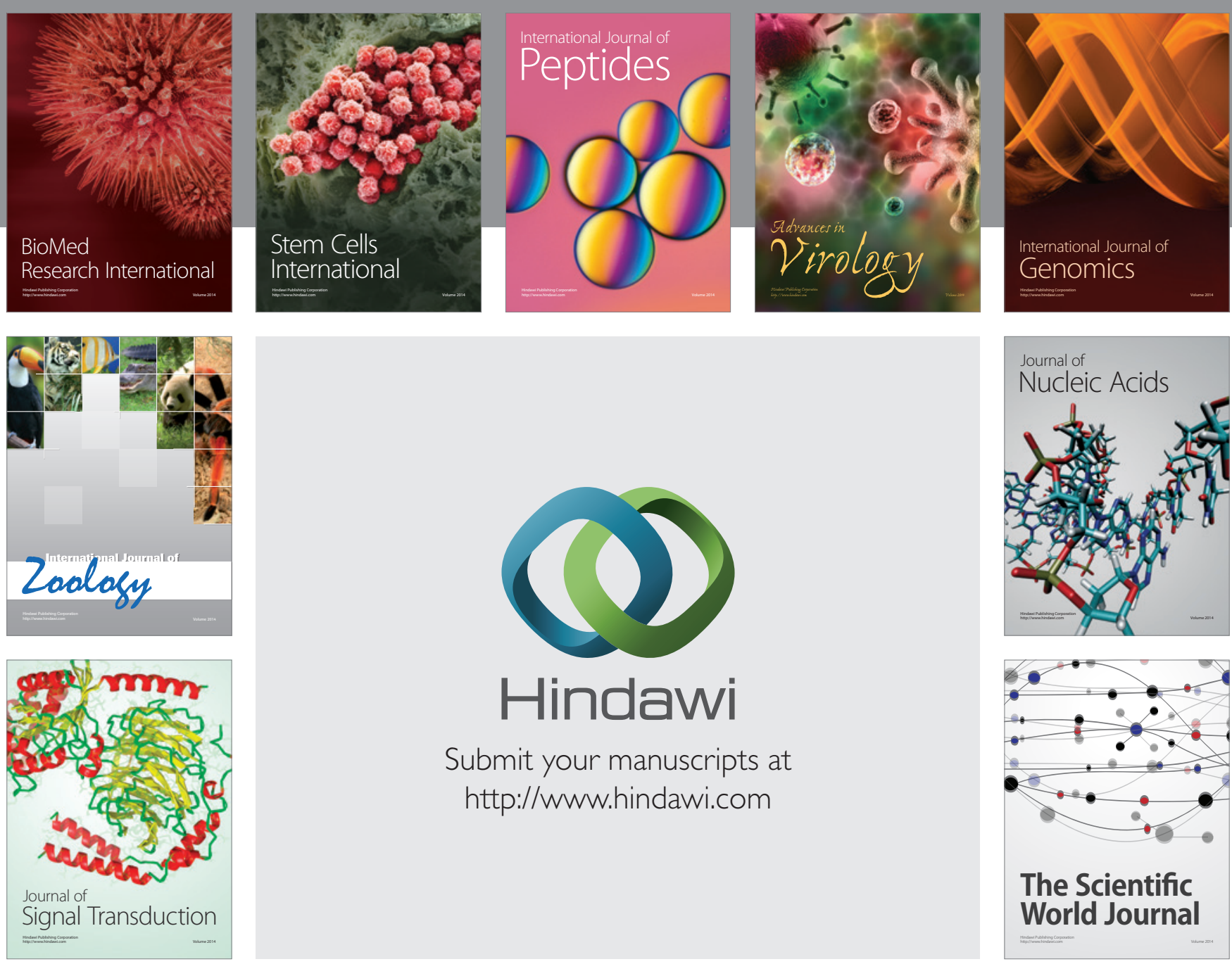

Submit your manuscripts at

http://www.hindawi.com
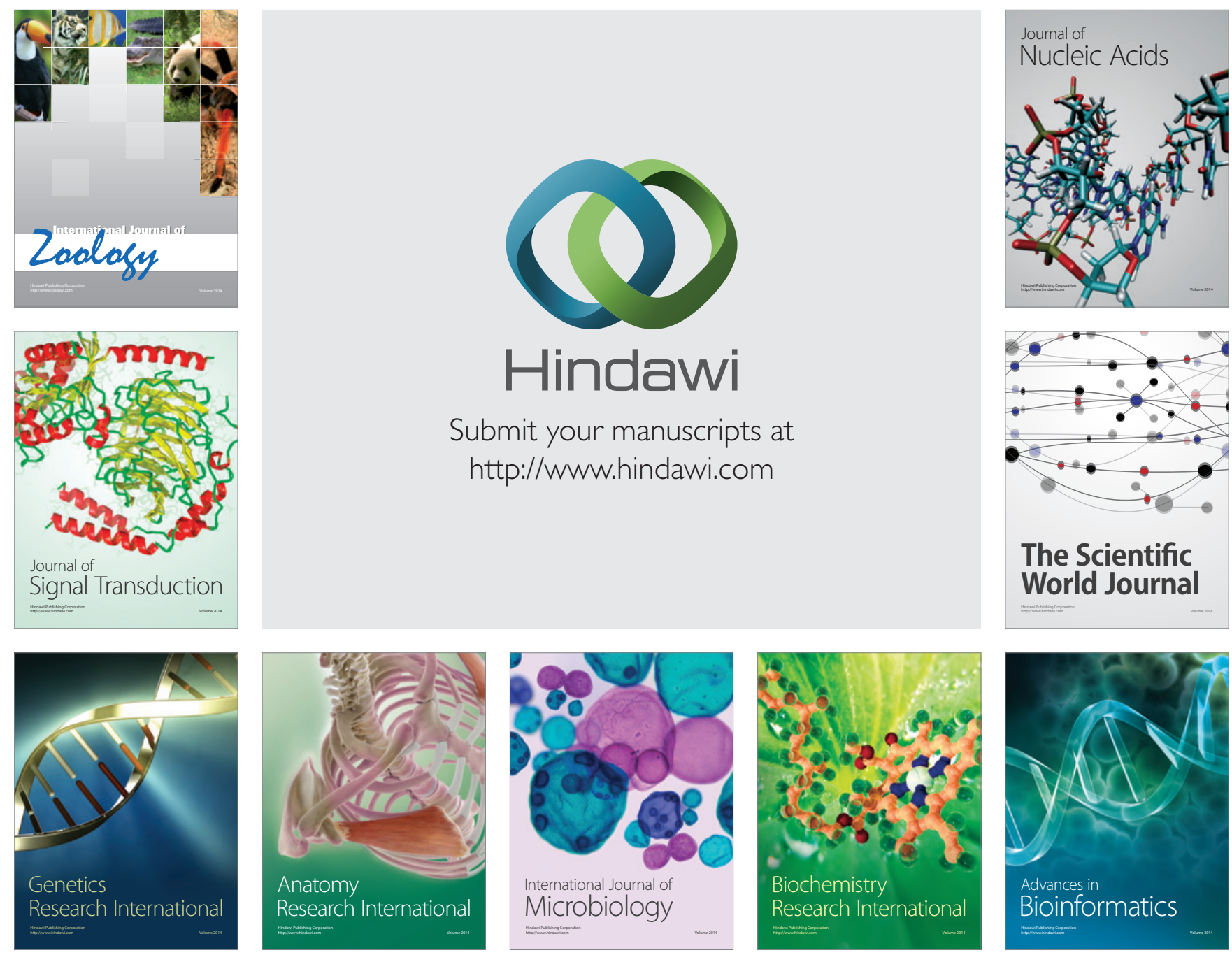

The Scientific World Journal
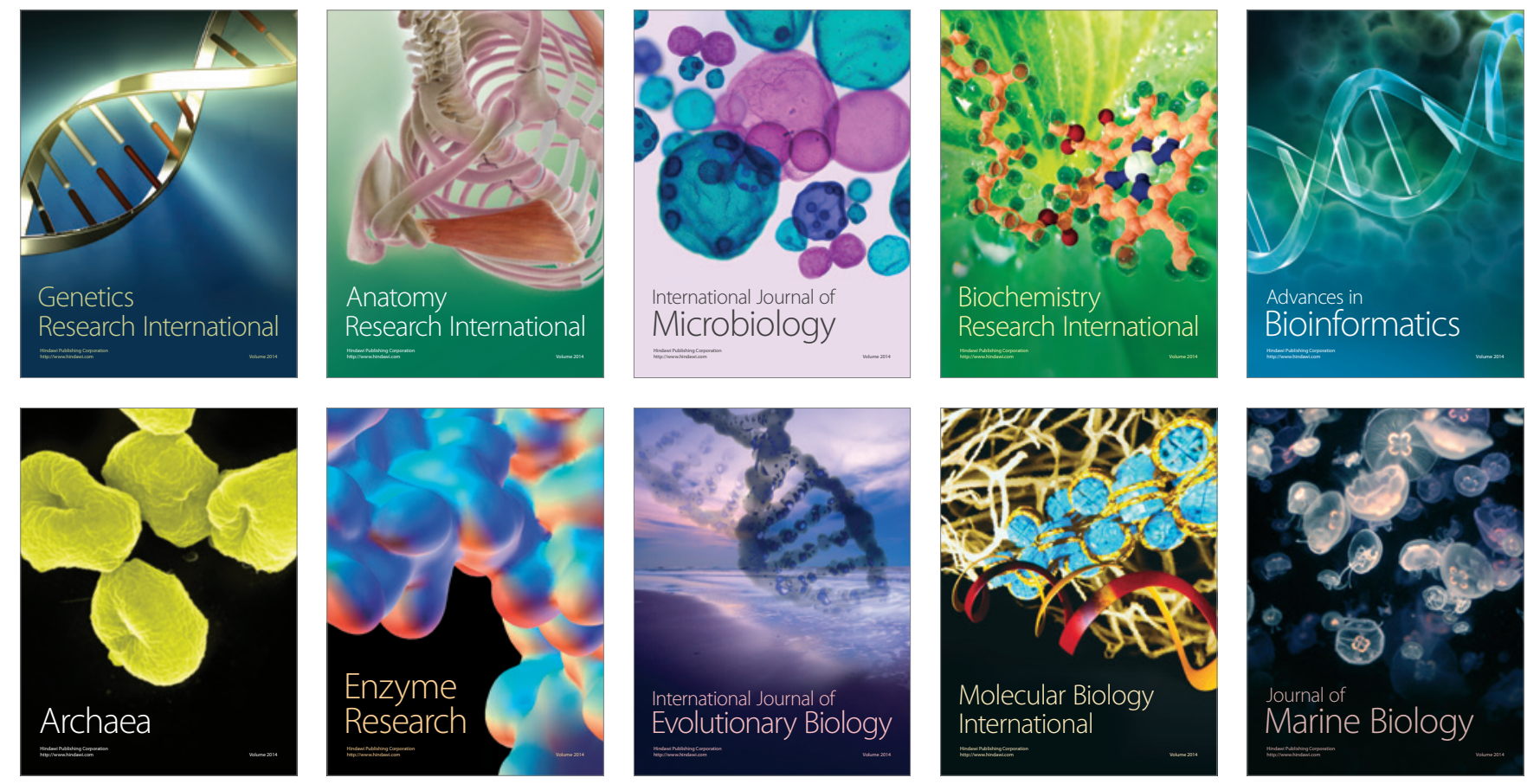